\title{
RESÍDUOS DE DELTAMETRINA EM GRÃOS DE TRIGO E EM SEUS PRODUTOS PROCESSADOS, DETERMINADOS POR CROMATOGRAFIA GASOSA
}

\author{
Luiz Roberto Pimentel Trevizan ${ }^{1,3 *}$; Gilberto Casadei de Baptista² \\ ${ }_{2}^{1}$ Pós-Graduando do Depto. de Entomologia, Fitopatologia e Zoologia Agrícola - USP/ESALQ. \\ ${ }^{2}$ Depto. de Entomologia, Fitopatologia e Zoologia Agrícola - USP/ESALQ, C.P. 9 - CEP: 13418-900 - Piracicaba, SP. \\ Bolsista CNPq. \\ *Autor correspondente <lrptrevi@carpa.ciagri.usp.br>
}

RESUMO: O objetivo do presente estudo foi avaliar a degradação/persistência do inseticida piretróide deltametrina em grãos de trigo e em seus produtos processados, a saber: farelo, farinha branca, farinha integral e pão. Os grãos foram tratados de modo a alcançar a concentração teórica de $0,35 \mathrm{mg} \mathrm{kg}^{-1}$ do piretróide. As amostras foram tomadas a zero, 15, 30, 60 e 90 dias após a aplicação. Houve tendência de concentração do piretróide no farelo de trigo e um menor acúmulo nas farinhas, sendo que após o processo de cozimento do pão observou-se perda do inseticida.

Palavras-chave: piretróide, grão armazenado, farelo, farinha, pão

\section{DELTAMETHRIN RESIDUES IN WHEAT GRAINS AND THEIR PROCESSED PRODUCTS EVALUATED BY GAS CHROMATOGRAPHY}

\begin{abstract}
The objective of this research was to evaluate the degradation/persistence of the pyrethroid insecticide deltamethrin in wheat grains and their processed products: bran, white flour, whole meal flour and bread. The grains were treated to reach the theoretical concentration of $0.35 \mathrm{mg} \mathrm{kg}^{-1}$ of the insecticide. Samples were taken at zero, 15, 30,60 and 90 days after application. A higher pyrethroid concentration was observed in wheat bran and a lower accumulation in flour; insecticide loss was detected after bread baking.

Key words: deltamethrin, stored grains, bran, flour, bread
\end{abstract}

\section{INTRODUÇÃO}

Estima-se que $20 \%$ da produção nacional de grãos é perdida anualmente nos processos de colheita, de transporte e de armazenamento. Grande parte destas perdas deve-se a problemas fitossanitários, sendo somente as pragas de armazéns responsáveis por cerca de 10\% delas ou aproximadamente 7 milhões de toneladas de grãos.

Em razão dos problemas causados pelos insetos nos armazéns, tem-se usado principalmente substâncias químicas para controlar estas pragas e para preservação das colheitas; por outro lado, pode ocorrer a persistência destes inseticidas na forma de resíduos tóxicos nos grãos tratados, cujo consumo por parte do homem e dos animais, mesmo em quantidade sub-letais, representa risco potencial à saúde dos consumidores.

O controle oficial de resíduos de pesticidas em alimentos é geralmente baseado nas tolerâncias (limites máximos de resíduos) e períodos de carência (intervalos de segurança), estabelecidos caso a caso. Alguns estudos sobre a ocorrência de resíduos em grãos já são conhecidos entre nós. Entretanto, quase nada se sabe a respeito da ocorrência deles nos produtos processados e, em conseqüência, os riscos à saúde; de estudos estrangeiros, sabe-se que o processamento, em geral, reduz os resíduos nos produtos industrializados, mas em outros casos aumenta.
Bengston et al. (1983) encontraram aumento da concentração de deltametrina da ordem de 4,6 vezes no farelo de trigo e redução de cerca de 4 vezes na farinha branca, em relação ao grão; Holland et al. (1994) citam concentração dos resíduos do piretróide de 3,3, 0,71, 0,09, 0,31 e 0,06 vezes no farelo, nas farinhas (integral e branca) e pães (integral e branco), respectivamente; L'Hotellier (1983) cita aumento dos níveis residuais do piretróide de 4 a 7 vezes para o farelo e redução de 2,7 vezes para a farinha branca; Jermannaud \& Pochon (1994) relatam sendo 2,6 a 5,3 vezes a concentração de deltametrina no farelo, 0,84 na farinha integral e de $<0,04$ a 0,45 na farinha branca.

Com relação à degradação dos resíduos de deltametrina após cozimento, Bengston et al. (1983) relatam não ter ocorrido perdas do piretróide após essa operação; L'Hotellier (1983) considera que as perdas foram aparentes, devido à diluição do inseticida pela adição de água na composição do pão. Joia et al. (1985) registraram perdas de 21 e $13 \%$ de cipermetrina e fenvalerato para o pão integral a partir de sua farinha; Jermannaud \& Pochon (1994) relatam perdas variáveis de 0 a $70 \%$, para diversos tipos de pães; Holland et al. (1994) encontraram variações de 58 a $99 \%$ nessas perdas e Peixoto et al. (1995) obtiveram perdas de $15 \%$ após o cozimento de bolinhos de milho a partir de uma massa feita com fubá de milho. 
Justifica-se o presente trabalho, pela necessidade inadiável de se obter dados, nas condições brasileiras, sobre influência do processamento nos níveis de resíduos de pesticidas em produtos agrícolas usados na alimentação humana e animal, dados esses raros na literatura nacional.

Assim, foi conduzido o presente trabalho, cujo o principal objetivo foi estudar o comportamento do inseticida piretróide deltametrina em grãos de trigo e em seus produtos processados.

\section{MATERIAL E MÉTODOS}

Os experimentos foram desenvolvidos no Setor de Toxicologia de Inseticidas do Departamento de Entomologia, Fitopatologia e Zoologia Agrícola da Escola Superior de Agricultura "Luiz de Queiroz", da Universidade de São Paulo, em Piracicaba, com a colaboração da Cargill Agrícola S.A.

A deltametrina foi aplicada de modo a produzir concentração teórica de $0,35 \mathrm{mg} \mathrm{kg}^{-1}$ nos grãos. 0 delineamento experimental foi inteiramente ao acaso, com três repetições e os resíduos avaliados por período de 90 dias após o tratamento. O produto comercial utilizado foi o K-Obiol 25 CE ( $25 \mathrm{~g}$ de deltametrina $+250 \mathrm{~g}$ de PBO/ litro).

A aplicação foi realizada com um pulverizador costal mantido a pressão constante com $\mathrm{CO}_{2}$, utilizandose $300 \mathrm{ml}$ de emulsão inseticida (diluição 1:250 do produto comercial em água) para cada $60 \mathrm{~kg}$ de grãos (5L/ton.). Para cada operação de tratamento, os grãos foram acomodados e esparramados em fina camada sobre lençol plástico; após a aplicação, os grãos foram melhor misturados agitando-se-os com o auxílio de um rodo. Após o tratamento os grãos foram recolhidos em sacos plásticos pretos e armazenados sob balcão de laboratório.

As amostragens de grãos foram realizadas com zero, 15, 30, 60 e 90 dias após a aplicação, sendo, igualmente, destinadas amostras para processamento e obtenção de seus produtos processados. Estas, destinadas ao processamento, foram encaminhadas à Cargill Agrícola S.A., no município de Tatuí-SP. Para tanto, as amostras eram condicionadas a uma quantidade de água suficiente para elevar a umidade dos grãos até $15,5 \%$, sendo, ao depois, levadas à moagem em moinho, o qual fornecia a farinha branca, mistura farinha/farelo e o farelo, sendo a farinha integral obtida a partir da mistura desses três componentes na proporção de 85/7,5/7,5, respectivamente. O pão foi feito de modo caseiro, utilizando-se farinha branca e integral, água, fermento, gordura vegetal e açúcar, sendo a massa cozida a temperatura de $\pm 200^{\circ} \mathrm{C}$ durante \pm 40 minutos.

Para o acompanhamento das condições dos grãos, foram mensalmente feitas análises de umidade deles, no Setor de Sementes do Departamento de Produção Vegetal da ESALQ/USP, e coleta diária de dados de temperatura e umidade do local de armazenamento.
O método de análise, adaptado a partir de L'Hotellier (1983), consta da extração dos resíduos das amostras com uma mistura de hexano + éter etílico $(1 / 1$, $\mathrm{v} / \mathrm{v}$ ). A limpeza do extrato é feita com partição de $10 \mathrm{~mL}$ de hexano e $25 \mathrm{~mL}$ de acetonitrila, ambos saturados um com o outro, e coluna cromatográfica de sílica gel 60 (63$200 \mu \mathrm{m})$, preparada em seringa hipodérmica de plástico $(10 \mathrm{~mL})$, contendo cerca de $1 \mathrm{~g}$ desse material, sendo a eluição procedida com $10 \mathrm{~mL}$ de um mistura de hexano + éter etílico $(1 / 1, v / v)$.

As amostras foram analisadas por cromatografia em fase gasosa, usando-se cromatógrafo a gás, HP, modelo 6890, equipado com detector de captura de elétrons (micro-ECD, $\mathrm{Ni}^{63}$ ) e coluna cromatográfica megabore J\&W DB-1 de $5 \mathrm{~m}$ de comprimento, diâmetro de 0,53mm e 1,5 $\mu \mathrm{m}$ de espessura do filme, com injeções feitas em modo "splitless". As condições de operação do cromatógrafo foram: temperatura da coluna $=255^{\circ} \mathrm{C}$, temperatura do injetor $=250^{\circ} \mathrm{C}$, temperatura do detector $=300^{\circ} \mathrm{C}$, tempo de purga $=0,75$ minuto, range $=5$, atenuação de saída: 128 vezes; fluxo de gases ( $\mathrm{mL} \mathrm{min}^{-1}$.): $\mathrm{N}_{2}$ : 12,5 (arraste), 60 (make-up) e fluxo de purga $=20$. Nestas condições o tempo de retenção foi de 2 minutos e 05 segundos, aproximadamente. A quantificação foi feita por comparação das áreas dos picos cromatográficos das amostras e dos padrões, sendo estas, obtidas por um registrador e integrador processador, marca Varian-modelo 4400 , conectado ao cromatógrafo.

Através de estudos de fortificação dos substratos, os métodos analíticos mostraram limites de quantificação e recuperação média de 0,01 e 92; 0,01 e 100; 0,01 e 112; 0,01 e $110 ; 0,05 \mathrm{mg} \mathrm{kg}^{-1}$ e $80 \%$ para grãos de trigo, farinha branca, farinha integral, pão e farelo, respectivamente. Os cromatogramas típicos de cada substrato podem observados nas figuras $1,2,3,4$ e 5 .

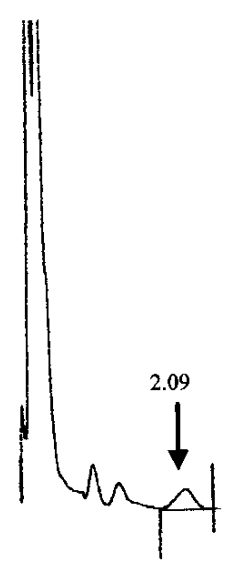

a

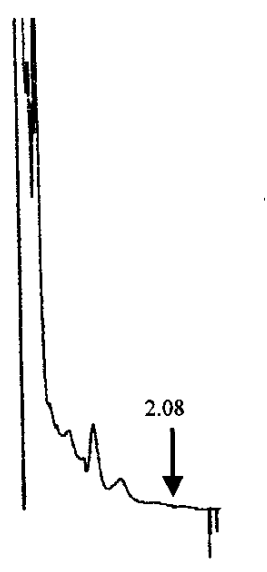

b

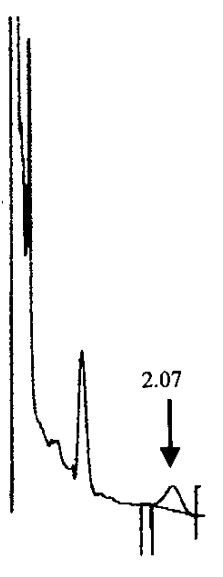

$\mathbf{c}$
Figura 1 - Cromatogramas de extratos de grãos de trigo. a) padrão $2 \mu \mathrm{l}-20 \mathrm{pg}$; b) testemunha $2 \mu \mathrm{l}-2 \mathrm{mg}$; c) fortificação $0,01 \mathrm{mg} \mathrm{kg}^{-1} / 2 \mu \mathrm{l}-2 \mathrm{mg}-20 \mathrm{pg}(\mathrm{mt})$. 


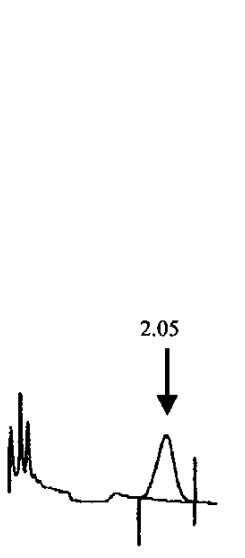

$\mathbf{a}$

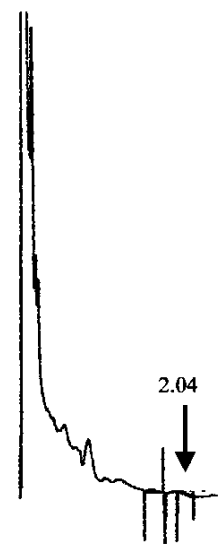

b c

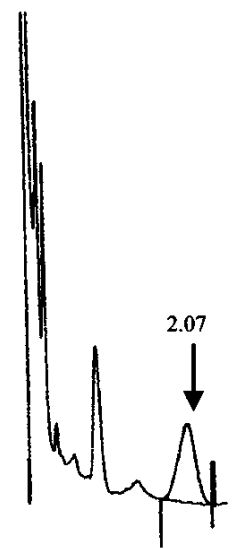

Figura 2 - Cromatogramas de extratos de farelo de trigo. a) padrão $1 \mu \mathrm{l}-50 \mathrm{pg}$; b) testemunha $1 \mu \mathrm{l}-1 \mathrm{mg}$; c) fortificação $0,05 \mathrm{mg} \mathrm{kg}^{-1} / 1 \mu \mathrm{l}-1 \mathrm{mg}-50 \mathrm{pg}(\mathrm{mt})$.

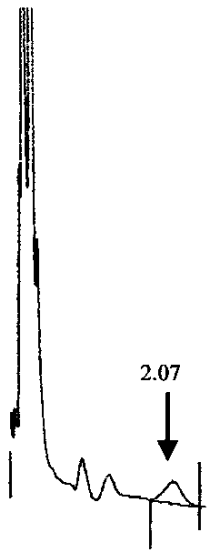

$\mathbf{a}$

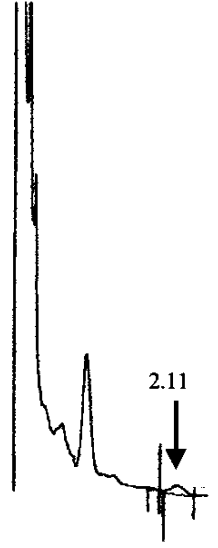

b

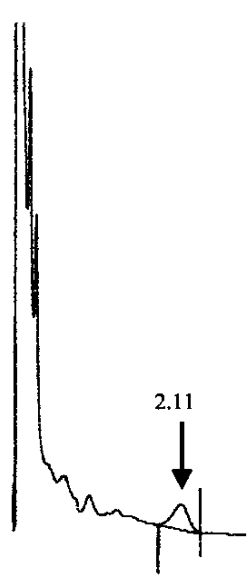

c
Figura 3 - Cromatogramas de extratos de farinha branca. a) padrão $2 \mu \mathrm{l}-20 \mathrm{pg}$; b) testemunha $2 \mu \mathrm{l}-2 \mathrm{mg}$; c) fortificação $0,01 \mathrm{mg} \mathrm{kg}^{-1} / 2 \mu \mathrm{l}-2 \mathrm{mg}-20 \mathrm{pg}(\mathrm{mt})$.

\section{RESULTADOS E DISCUSSÃO}

Os resultados obtidos das análises de grãos de trigo e de seus produtos processados feitas a zero, 15, 30,60 e 90 dias após a aplicação, são apresentados na TABELA 1.

Observa-se que da dosagem intencional de $0,35 \mathrm{mg} \mathrm{kg}^{-1}$ de deltametrina, recuperou-se, ao zero dia após a aplicação, $0,24 \mathrm{mg} \mathrm{kg}^{-1}$, ou seja, $69 \%$ da dosagem pretendida.

A análise conjunta das tabelas mostram uma persistência e estabilidade bastante evidentes nos grãos armazenados, ao longo do período de estudos (90 dias), com variações de 0,22 a $0,27 \mathrm{mg} \mathrm{kg}^{-1}$.

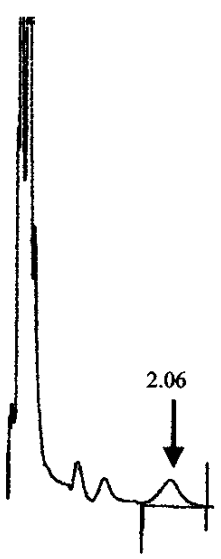

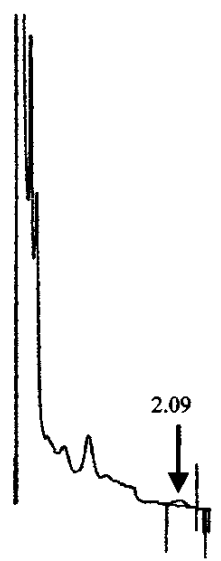

b

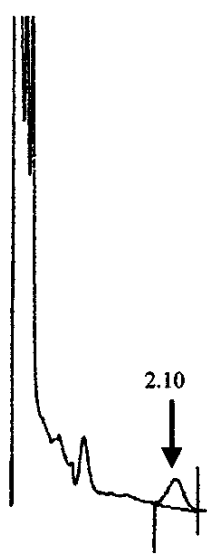

Figura 4 - Cromatogramas de extratos de farinha integral. a) padrão $2 \mu \mathrm{l}-20 \mathrm{pg}$; b) testemunha $2 \mu \mathrm{l}-2 \mathrm{mg}$; c) fortificação $0,01 \mathrm{mg} \mathrm{kg}^{-1 / 2} 2 \mu \mathrm{l}-2 \mathrm{mg}-20 \mathrm{pg}(\mathrm{mt})$.

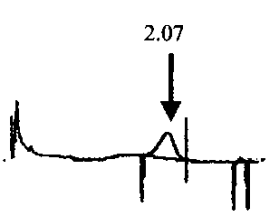

a

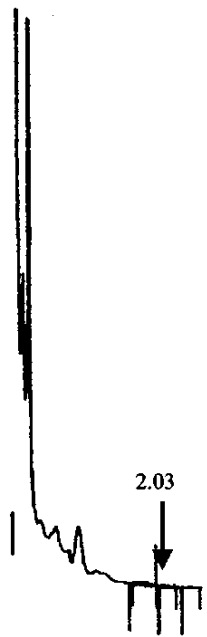

$\mathbf{b}$

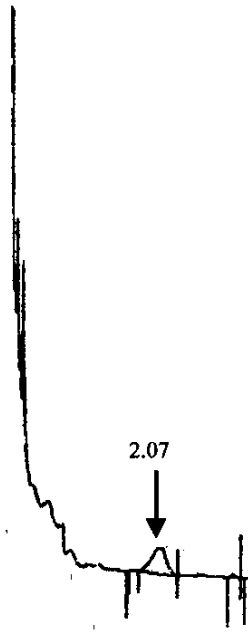

c
Figura 5 - Cromatogramas de extratos de pão integral. a) padrão $2 \mu \mathrm{l}-20 \mathrm{pg}$; b) testemunha $2 \mu \mathrm{l}-2 \mathrm{mg}$; c) fortificação $0,01 \mathrm{mg} \mathrm{kg}^{-1} / 2 \mu \mathrm{l}-2 \mathrm{mg}-20 \mathrm{pg}(\mathrm{mt})$.

A deltametrina mostrou tendência de se concentrar nas partes mais externas e oleosas do grão, pericarpo e gérmen, e em menor escala no endosperma, resultando uma concentração do inseticida da ordem de 2,12 vezes no farelo e redução média de $52,4 \%$ na farinha branca e $42,4 \%$ na integral. Se comparado com os resíduos contidos nos grãos, o pão integral mostrou redução de $84,6 \%$ nos níveis residuais, sendo esta de $69 \%$ quando comparado com as farinhas usadas na sua produção. Esses valores diferem daqueles encontrados por Bengston et al. (1983), de Holland et al. (1994) e de L'Hotellier (1983), sendo compatíveis com os de Jermannaud \& Pochon (1994). 
TABELA 1 - Resíduos de deltametrina em grãos de trigo e produtos processados.

\begin{tabular}{|c|c|c|c|}
\hline Dias após o tratamento & Substrato & Média $\left(\mathrm{mg} \mathrm{kg}^{-1}\right) \mathrm{m} \pm \mathrm{s}$ & Índice de concentração de resíduos \\
\hline & grão & $0,24 \pm 0,02$ & 1 \\
\hline & farelo & $0,57 \pm 0,02$ & 2,39 \\
\hline \multirow[t]{5}{*}{ zero } & farinha branca & $0,13 \pm 0,03$ & 0,54 \\
\hline & farinha integral & $0,16 \pm 0,02$ & 0,67 \\
\hline & pão & $0,07 \pm 0,01$ & 0,29 \\
\hline & grão & $0,27 \pm 0,02$ & 1 \\
\hline & farelo & $0,60 \pm 0,02$ & 2,22 \\
\hline \multirow[t]{5}{*}{15} & farinha branca & 0,11 & 0,41 \\
\hline & farinha integral & $0,16 \pm 0,01$ & 0,59 \\
\hline & pão & $0,04 \pm 0,01$ & 0,15 \\
\hline & grão & $0,24 \pm 0,01$ & 1 \\
\hline & farelo & $0,56 \pm 0,01$ & 2,33 \\
\hline \multirow[t]{5}{*}{30} & farinha branca & 0,10 & 0,42 \\
\hline & farinha integral & $0,14 \pm 0,01$ & 0,58 \\
\hline & pão & $0,03 \pm 0,01$ & 0,13 \\
\hline & grão & $0,26 \pm 0,01$ & 1 \\
\hline & farelo & $0,43 \pm 0,01$ & 1,65 \\
\hline \multirow[t]{5}{*}{60} & farinha branca & $0,11 \pm 0,01$ & 0,42 \\
\hline & farinha integral & 0,13 & 0,50 \\
\hline & pão & 0,03 & 0,12 \\
\hline & grão & $0,22 \pm 0,01$ & 1 \\
\hline & farelo & $0,44 \pm 0,02$ & 2,00 \\
\hline \multirow[t]{3}{*}{90} & farinha branca & $0,09 \pm 0,01$ & 0,41 \\
\hline & farinha integral & $0,12 \pm 0,01$ & 0,54 \\
\hline & pão & 0,02 & 0,1 \\
\hline
\end{tabular}

$\mathrm{m}$ = média; $\mathrm{s}=$ desvio padrão da média

Pode-se supor que essas diferenças sejam decorrentes da metodologia e do tipo e/ou modelo de moinho usado para se obter as frações moídas do grão de trigo, bem como uma diferença entre variedades, resultando assim em diferentes níveis de absorção do inseticida para as partes mais internas do grão, como os resultados obtidos por McGaughey (1971), em que as variedades de arroz que possuíam casca menos espessa apresentavam penetração mais intensa de malation para o interior do grão.

O maior nível de resíduo encontrado na farinha branca, e consequentemente o menor encontrado no farelo, em relação a outros trabalhos, pode ainda estar relacionado à uma absorção do inseticida pelo endosperma durante o processo de condicionamento dos grãos para aumento de umidade, já que Cogburn et al. (1990) observaram que o arroz parbolizado continha uma quantidade maior de malation e de clorpirifós nas suas frações mais internas do que $o$ arroz não parbolizado.

Com relação aos dados de degradação dos resíduos de deltametrina após o cozimento, os resultados encontrados no presente trabalho estão dentro dos níveis relatados por Jermannaud \& Pochon (1994) e de Holland et al. (1994), não concordando com os de Bengston et al. (1983), de L'Hotellier (1983) e de Peixoto et al. (1995).

Provavelmente as variações de resíduos de deltametrina nos diversos trabalhos, devem-se às diferentes receitas de pães, podendo variar a quantidade de água utilizada e a temperatura de cozimento. No experimento aqui descrito pode-se citar como fatores da diminuição do nível residual de deltametrina no pão, a sua maior umidade em relação as farinhas e a temperatura de cozimento, de $\pm 200^{\circ} \mathrm{C}$ durante 40 minutos, já que temperaturas acima de $190^{\circ} \mathrm{C}$ acarretam perdas significantes deste piretróide (Tessier, 1983).

Os resíduos encontrados nos grãos de trigo mostraram-se, obviamente, bem menores do que a tolerância estabelecida pela legislação brasileira, de $1 \mathrm{mg} \mathrm{kg}^{-1}$, para grãos armazenados. A indicação agronômica $\left(0,35 \mathrm{mg} \mathrm{kg}^{-1}\right)$ comparada à tolerância legal $\left(1 \mathrm{mg} \mathrm{kg}^{-1}\right)$, a princípio, permite o consumo dos grãos logo após o tratamento; isto indica que a legislação pertinente necessita ser coerentemente adequada ao uso do inseticida em grãos armazenados. 
Para os produtos obtidos através da moagem de grãos de trigo não se tem dados sobre os limites máximos de resíduos na legislação nacional, necessitando-se, para fins comparativos, fazer uso dos dados fornecidos pelo Codex Alimentarius da FAO (1998), onde tem-se como sendo de 5 e $0,2 \mathrm{mg} \mathrm{kg}^{-1}$ a tolerância para farelo e farinha branca, respectivamente. Observa-se, assim, que ambos os substratos analisados tiveram resíduos sempre inferiores àqueles limites estabelecidos pela $\mathrm{FAO}$, durante todo o período de análises (90 dias). Apesar de ser atualmente o mais importante inseticida para grãos armazenados, os dados sobre tolerância em produtos derivados de grãos tratados no armazenamento deixam a desejar em relação a outros produtos, uma vez que já se os têm em maiores freqüências para tais inseticidas como fenitrotion e pirimifós-metil.

\section{CONCLUSÕES}

- O método analítico empregado para análise de resíduos de deltametrina em grãos de trigo, e em seus produtos processados, mostra-se adequado, com limites de quantificação variáveis de 0,01 a $0,05 \mathrm{mg} \mathrm{kg}^{-1}$.

- Resíduos de deltametrina são estáveis em grão sob condições de armazenamento, por período de 90 dias ou mais.

- Os resíduos de deltametrina em grãos de trigo concentram-se preferencialmente no farelo e em menores quantidades nas farinhas, sendo que 0 processo de cozimento do pão causa degradação desse inseticida.

\section{AGRADECIMENTOS}

Os autores agradecem à Cargill Agrícola S.A. por sua colaboração na obtenção dos diversos substratos utilizados no trabalho e a FAPESP pelo apoio financeiro.

\section{REFERÊNCIAS BIBLIOGRÁFICAS}

BENGSTON, M.; DAVIES, R.A.H.; DESMARCHELIER, J.M.; HENNING, R.; MURRAY, W.; SIMPSON, B.W.; SNELSON, J.T.; STICKA, R.; WALLBANK, B.E. Organophosphorothioates and synergised synthetic pyrethroids as grain protectants on bulk wheat. Pesticide Science, v.14, p.373-384, 1983.

COGBURN, R.R.; SIMONAITIS, R.A.; WEBB, B.D. Fate of malathion and chlorpirifos methyl in rough rice and milling fractions before and after parboiling and cooking. Journal of Economic Entomology, v.83, p.1636-1639, 1990.

FAO. Codex alimentarius: Pesticide Residues in Food; maximum residue limits. extraneous maximum residue limits. In: http:// apps.fao.org/cgi-bin/nph-db.pl (1998).

HOLLAND, P.T.; HAMILTON, D.; OHLIN, B.; SKIDMORE, M.W. Effects of storage and processing on pesticide residues in plant products. Pure and Applied Chemistry, v.66, p.335-356, 1994.

JERMANNAUD, A.; POCHON, J.M. The fate of residues of deltamethrin in treated wheat during its transformation into food products. In: INTERNATIONAL WORKING CONFERENCE ON STORED-PRODUCTS PROTECTION, 6., Camberra, 1994. Proceedings. Wallingford: CAB International, 1994. v.2, p.798-803.

JOIA, B.S.; WEBSTER, G.R.B.; LOSHIAVO, S.R. Cypermethrin and fenvalerate residues in stored wheat and milled fractions. Journal of Agricultural and Food Chemistry, v.33, p.618-622, 1985.

L'HOTELLIER, M. Los residuos de deltametrín en los vegetales y otros productos alimenticios. In: RUSSEL UCLAF. Deltametrín: monografía. Saint-Pierre: Aubanel, 1983. cap.8, p.287-324.

McGAUGHEY, W.H. Malathion on milling fractions of three varieties of rough rice: Duration of protection and residues degradation. Journal of Economic Entomology, v.64, p.1200-1205, 1971.

PEIXOTO, T.M.A.G.; FRANKLIN, H.M.O.H.; SANTOS, J.P.; NELSON, D.L. Influência do processamneto e da temperatura sobre os resíduos de deltametrina em produtos preparados a partir de milho tratado. In: ENCONTRO NACIONAL DE ANALISTAS DE RESÍDUOS DE PESTICIDAS, 18., São Paulo, 1995. Relatório. São Paulo: Instituto Adolfo Lutz, 1995. p.112-120.

TESSIER, J. Estructura, sintesis y propriedades fisico-quimicas del deltametrín. In: RUSSEL UCLAF. Deltametrín. SaintPierre: Aubanel, 1983. cap.2, p.37-66.

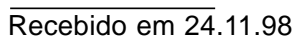

